\title{
CFD for Helical Type Vertical Axis Wind Turbine
}

\author{
L.Prabhu, Sangeetha Krishnamoorthi, Md.Shaheen Ansari, Hari Krishna aravind, Jishnu
}

\begin{abstract}
Vertical axis wind turbines are most effective for home energy generation especially in urban environments. Wind energy creates a stand-alone energy source that is relied on any place. The main criteria for this work is the design of micro wind turbines for all kinds of applications. Design of Twisted Blade Micro-Wind Turbine system is accomplished using computer aided design with Computational Fluid Dynamics (CFD). The flow characteristics in the wind turbine blade were analyzed by varying its twist ratio. The wind turbines with vertical axis utilize the wind from any direction with no yaw mechanism. The risk of blade ejection besides catching wind from all the directions is avoided by using the helical tye vertical axis wind turbine.
\end{abstract}

Keywords : Vertical axis wind turbine, Computational Fluid Dynamics, Ansys.

\section{INTRODUCTION}

$\mathrm{T}$ he most promising renewable energy source is wind energy which is used to produce mechanical energy and windmill is used to change the K.E of the blowing wind into mechanical energy[1]-[2]. Generator is used to convert the kinetic energy contained in the air to electricity. The torque is exerted on a rotor by allowing the wind to blow past the moving blades[3]-[4]. The rotor size and the wind speed define the amount of power transferred. Greenhouse gas emissions can reduce by the effective use of wind energy by replacing fossil-fuel-derived electricity[5]-[6]. Vertical axis twisted windmill is used to study about the flow characteristics and hence the performance is evaluated[7].

\section{OBJECTIVE}

To analyze the flow characteristics of wind around the helical type wind turbine using CFD

a) To evaluate the performance by varying the following parameter (a) twist ratio

- To optimize the wind turbine dimensions to enhance its performance.

Figure 1 shows the vertical axis twisted wind mill

Revised Manuscript Received on December 16, 2019

* Correspondence Author

L.Prabhu*, Professor, Department of Mechanical Engineering, Aarupadai veedu Institute of Technology, Vinayaka Mission's Research Foundation, Chennai, India, prabhu@avit.ac.in

S.Sangeetha*, Assistant Professor, Department of Mechanical Engineering, Aarupadai veedu Institute of Technology, Vinayaka Mission's Research Foundation, Chennai, India,

Md.Shehen Ansari, Hari Krishna aravind, Jishnu, UG Scholar, Department of mechanical Engineering , Aarupadai veedu Institute of Technology, Vinayaka Mission's Research Foundation, Chennai, India

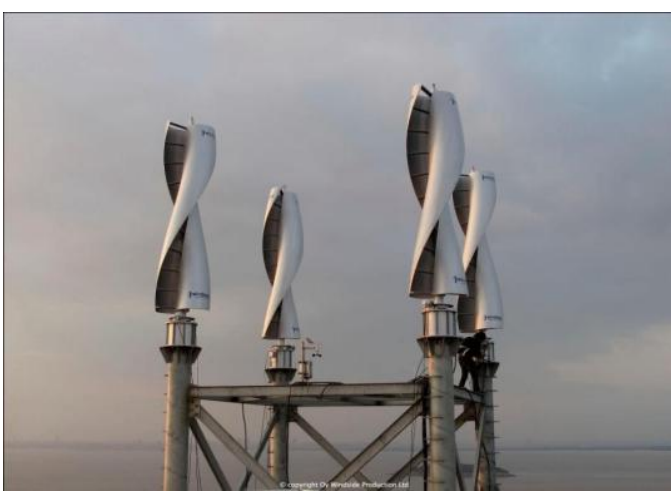

Fig. 1.Vertical axis twisted wind mill .

\section{METHODS AND MATERIALS}

\section{A. CFD Analysis Meshing}

Figure 2 shows the Pro E Patterns of Wind Turbine with pattern 1,2,3,4.Similarly Figure 3 shows the meshed patterns. b) a)

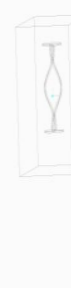




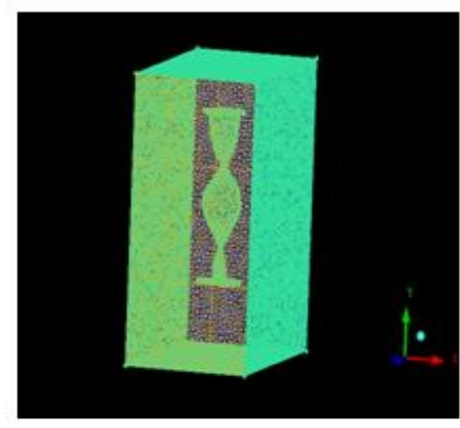

a)

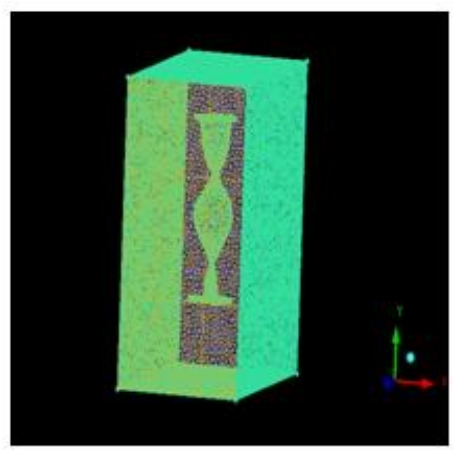

b)

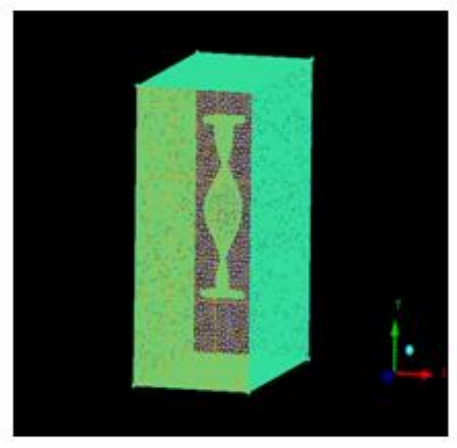

c)

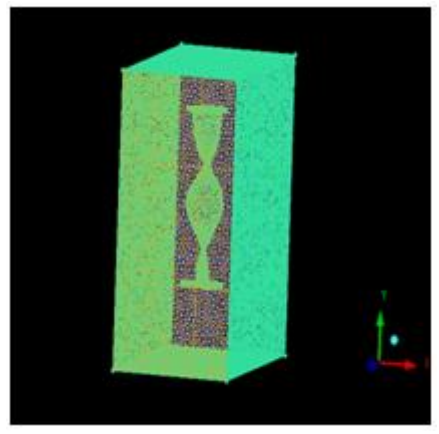

d)

Fig. 3.Meshed Patterns (a) Pattern 1 (b) Pattern 2 (c) pattern 3 (d)pattern 4 .

\section{CFX -PRE PROCESSING}

Figure 4 shows the CFX preprocessing for Mesh patterns

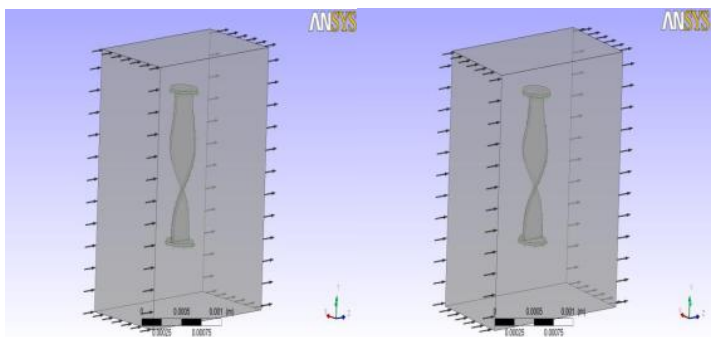

b)

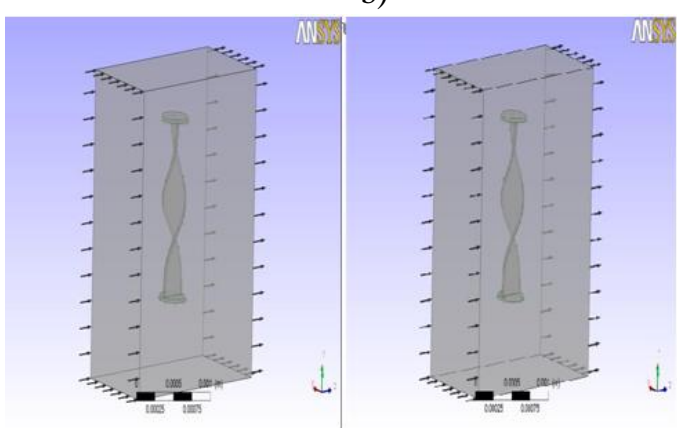

c)

d)

Fig. 4.Meshed Patterns (a) Pattern 1 (b) Pattern 2 (c) pattern 3 (d) pattern 4 .

Using Create Material option the physical properties of air are specified. The fluid and solid domains are defined using Create Domain option. The inlet and Outlet boundary conditions are defined by using Define Boundary Conditions options. The domain interfaces are connected by specifying the fluid solid interface type.

\section{RESULT AND DISCUSSION}

Figure 5 shows the velocity distribution with pattern $1,2,3$, and 4 .

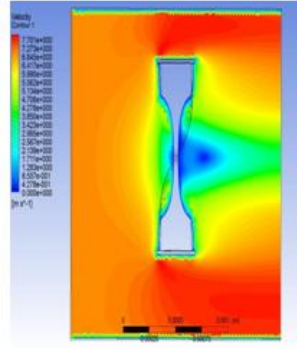

a)

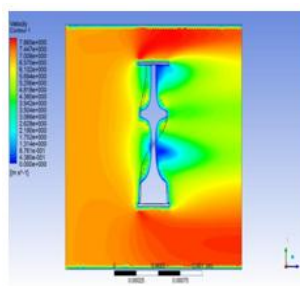

c)

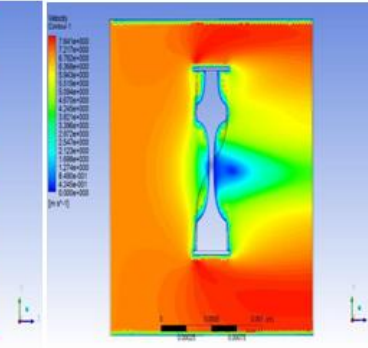

b)

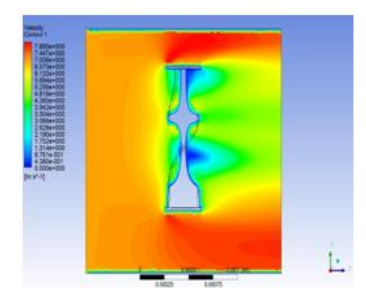

d)
Fig. 5.Velocity Distribution (a) Pattern 1 (b) Pattern 2 (c) pattern $3(d)$ pattern 4 . 
Table- II: Name of the Table that justify the values

\begin{tabular}{|c|c|c|c|c|c|}
\hline \multirow{2}{*}{ S.No } & $\begin{array}{c}\text { Descriptio } \\
\mathrm{n}\end{array}$ & \multicolumn{4}{|c|}{ Inlet velocity $\mathrm{m} / \mathrm{s}$} \\
\cline { 3 - 6 } & & 4 & 7 & 10 & 13 \\
\hline 1 & Pattern 1 & 4.406 & 7.914 & 11.448 & 14.987 \\
\hline 2 & Pattern 2 & 4.367 & 7.853 & 11.291 & 14.764 \\
\hline 3 & & & & & \\
\hline 4 & Pattern 3 & 4.318 & 7.907 & 11.453 & 15.007 \\
\hline
\end{tabular}

Tables 1 and 2 shows the velocity variations and its ouput power.

Table- II: Name of the Table that justify the values

\begin{tabular}{|c|c|c|c|c|c|}
\hline \multirow{2}{*}{$\begin{array}{c}\text { S.N } \\
0\end{array}$} & Description & \multicolumn{4}{|c|}{ Inlet velocity $\mathrm{m} / \mathrm{s}$} \\
\cline { 3 - 6 } & & 4 & 7 & 10 & 13 \\
\hline 1 & Pattern 1 & 5.181 & 9.307 & 13.463 & 17.625 \\
\hline 2 & Pattern 2 & 5.136 & 9.235 & 13.278 & 17.362 \\
\hline 3 & Pattern 3 & 5.078 & 9.299 & 13.469 & 17.648 \\
\hline 4 & Pattern 4 & 5.207 & 9.529 & 13.822 & 18.162 \\
\hline
\end{tabular}

Fig. 6 shows the various output power obtained against wind turbine rotor for different patterns mentioned before. The variation in output power is marginal at lower velocities among the wind turbine patterns. The power output is relatively higher for the pattern 4 when increasing the inlet velocity.

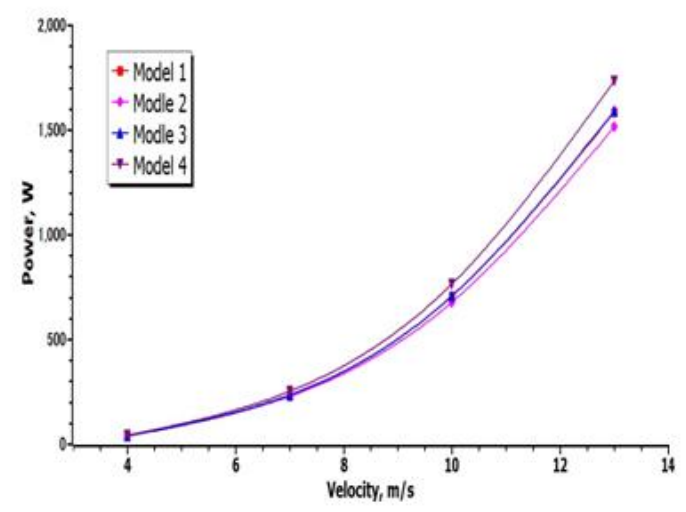

Fig. 6.Power Output For Varying Inlet Velocity.

\section{CONCLUSION}

The CFD analysis of twisted blade wind turbine was carried and the following conclusion has been be drawn

- Increased turbulence at downstream of the rotor of wind turbine causes wake formation which draws more air.

- The presence of recirculation zones are relatively higher for the pattern 4

- The variation in output power is marginal at lower velocities among the wind turbine patterns.

- The increase in power output for the pattern 4 is $6.61 \%$ compared with pattern 1

\section{REFERENCES}

1. I. Paraschivoiu" Double-Multiple Streamtube Pattern for Darrieus Wind Turbines", Institute de Recherché d'Hydro-Québec,Canada,pp.15-64.

2. R. J. Templin ," Aerodynamic performance theory for the NRC vertical-axis wind turbine", NASA STI/RECON technical report.76, Jun. 1974.

3. J. H. Strickland," Darrieus turbine: a performance prediction model using multiple streamtubes", Sandia Labs., Mex.(USA),Oct.1975

4. R. E. Sheldahl," Aerodynamic characteristics of seven airfoil sections through 180 degrees angle of attack for use in aerodynamic analysis of vertical axis wind turbines",1981, SAND80-2114.

5. P. C. Klimas ,R. E. Sheldahl," Four aerodynamic prediction schemes for vertical-axis wind turbines: A compendium", Department of Energy,Jun.1978 .

6. R. McGowan ,R. Lozano, V. Raghav ,N. Komerath," Vertical axis micro wind turbine design for low tip speed ratios", Georgia Institute of Technology Atlanta, United States,Mar.2012.

7. I. Paraschivoiu ,O. Trifu ,F. H. Saeed ,'Darrieus wind turbine with blade pitch control", International Journal of Rotating Machinery,2009.

\section{AUTHORS PROFILE}

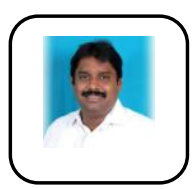

L.Prabhu*, Professor, Department of Mechanical Engineering, Aarupadai veedu Institute of Technology, Vinayaka Mission's Research Foundation, Chennai, India, prabhu@avit.ac.in.

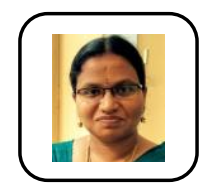

Sangeetha Krishnamoorthi, Associate Professor, Department of Mechanical Engineering, Aarupadai Veedu Institute of Technology, Vinayaka Mission Research Foundation.

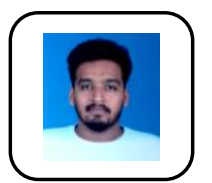

Md.Shehen Ansari ,UG Student, Department of Mechanical Engineering, Aarupadai Veedu Institute of Technology, Vinayaka Mission Research Foundation.

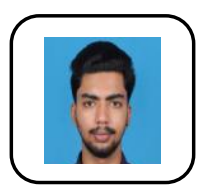

Hari Krishna aravind, UG Student, Department of Mechanical Engineering, Aarupadai Veedu Institute of Technology, Vinayaka Mission Research Foundation. 